\title{
Complexities with restricted numeral systems
}

MARK DONOHUE

Abstract

The cognitive advantages to retaining a restricted counting system (without exponentiation) even as a more complicated one is being developed are not im mediately obvious, but follow from the information about upcoming complexity that is implicit in the use of distinct numerals. Kanum, a language from the south of New Guinea, where "systems with limited extent" are widely reported, has base-6 counting systems with full use of exponentiation in one system, and no possibility of extension in another. The evidence suggests the more complex systems were internally motivated, yet the simpler systems have not been abandoned.

Keywords: Kanum, New Guinea, number systems, numerals

\section{Introduction}

What implications does the presence of a complex numeral system in a language have? Early typologies of counting (Crawfurd 1863) imply a lineal movement towards more complex, but the facts are not so simple. Restricted or object-specific counting systems can survive while a complex system develops. Object-specific counting sequences can be cognitively advantageous; Beller \& Bender (2008) contrast the decimal system of Mangareva with the "systems with limited extent" from New Guinea. While it is true that New Guinea contains many restricted numeral systems (Laycock 1975, Lean 1992, Comrie 2005), the region is not homogeneous, including systems that allow for higher numerals without being decimal (or decimal-derived). 
Table 1. Numerals in One

\begin{tabular}{lllll}
\hline 1 & ara & 1 & & \\
2 & plana & 2 & *ara plana & $1+2$ \\
3 & plana ara & $2+1$ & *ara plana ara (etc.) & $1+2+1$ \\
4 & plana plana & $2+2$ & *plana ara plana $(\mathrm{etc})$ & $2+1+2$ \\
5 & plana plana ara & $2+2+1$ & *plana plana plana $(\mathrm{etc})$ & $2+2+2$ \\
6 & plana ara plana ara & $(2+1)+(2+1)$ & * \\
\hline
\end{tabular}

\section{Non-decimal numeral systems of New Guinea}

Even among those languages with "restricted" systems there are often culturally-determined patterns of organisation. The One language (Torricelli family; the variety reported here is spoken in Molmo village, though other varieties have similar, if not identical, systems) exemplifies a typical restricted system. In One only two numerals are found (ara 'one' and plana 'two'); 'three' is always constructed as $2+1$, and not $1+2$, for instance, and 'four' as $2+2$, never $1+2+1$ (or various other mathematically possible combinations). As shown in Table 1, 'five' is $2+2+1$. Notably, 'six' is most generally accepted as $(2+1)+(2+1)$, and not $* 2+2+2$, indicating that there are the beginnings of a base beyond the highly restricted system with just two terms.

Using combinations of numerals to count above six is rare in One culture, and indeed any number higher than two can be referred to with тори 'many', тори-тори 'many', or moplo 'many-PLURAL'. This does not mean that people are not capable of keeping careful track of precisely how much is owed to which parties in any transaction, with quantities reckoned routinely extending up to and beyond 50 , indicating that the absence of verbal representation for numerals does not indicate their psychological absence (consistent with the discussion in Gelman \& Gallistel 2004). The highlands of New Guinea are famous for their use of extended body part systems (Laycock 1975), and the western Skou languages of the North-central coast count using variations on a base-4/8/12/24 system (own fieldnotes, Donohue 2004). In Skou itself the base4 has developed into a base-5, but the earlier base is apparent in the compound referring to 'seven', which employs a 'plus three', not 'plus two' (Table 2).

Note that in Skou the counting system is restricted; it counts to mabirí ' 24 ', but it is not possible to construct, for instance, mabirí pa áling ' $24+1$ ' to refer to 25; past 24 nawò 'many' or fátà 'all' are the only quantifiers possible, short of switching into Papuan Malay, which is universally understood. Regardless of these intriguing aspects, the Kanum of the south coast have what is perhaps the most interesting numeral system for the purposes of this article.
Table 2. Numerals in Skou

\begin{tabular}{|c|c|c|c|c|c|}
\hline 1 & áling & 1 & 13 & hangpà pa áling & $12+1$ \\
\hline 2 & hingtung & 2 & 14 & hangpà pa hìngtung & $12+2$ \\
\hline 3 & héngtong & 3 & 15 & hangpà pa héngtong & $12+3$ \\
\hline 4 & nongpong & 4 & 16 & hangpà pa nongpong & $12+4$ \\
\hline 5 & nápang & 5 & 17 & hangpà pa nápang & $12+5$ \\
\hline 6 & nápánghi & $5+n$ & 18 & hangpà pa nápang pa áling & $12+5+1$ \\
\hline 7 & nápang héngtong & $5+3$ & 19 & hangpà pa nápang pa héngtong & $12+5+3$ \\
\hline 8 & náhìpa & 8 & 20 & hangpà pa náhìpa & $12+8$ \\
\hline 9 & náhìpa pa áling & $8+1$ & 21 & hangpà pa náhìpa pa áling & $12+8+1$ \\
\hline 10 & náhìpa pa hìngtung & $8+2$ & 22 & hangpà pa náhìpa pa hìngtung & $12+8+2$ \\
\hline 11 & náhipa pa héngtong & $8+3$ & 23 & hangpà pa náhìpa pa héngtong & $12+8+3$ \\
\hline 12 & hangpà & 12 & 24 & mabirí & 24 \\
\hline
\end{tabular}

\section{Kanum numerals}

In Kanum ${ }^{1}$ a set of six numerals allows for counting up to six, as shown in Table 3; this set does not extend, and swabra 'five' can be related to swa 'hand', a clear reference to five fingers. A clue to the existence of a base- 6 system can be found in the system of finger-counting. When counting, the fingers are used as follows: first, the left thumb is extended, then the forefinger of the same hand, the middle finger, the ring finger, and the little finger, in that order; then for six the now fully-extended digits of the left hand grasp the wrist of the right hand. ${ }^{2}$ The counting begins again with the left hand if the speaker wishes to go beyond six.

Counting beyond six and up to twelve, a second set of numerals, here called the "moderate" set, must be used. There are six basic numerals, of which only 'four' is identical to the form in the simple set. Differences between the forms in the simple set and the moderate set might be due to dialect borrowing; aempy is the form for 'one' in the simple set of the eastern dialects spoken near Kurkari and Sota, for instance, and the same is true for 'three' and 'five'. 'Two' is apparently made of ynao- plus the form for 'one', though no meaning can be ascribed to the putative formative ynao-. A suppletive form, pysymery

1. Kanum data is, unless otherwise stated, drawn from Yanggandur dialect. Forms are cited in a variant of the practical orthography, in which $\langle a e\rangle$ represents the low front vowel, and $\langle a 0\rangle$ the low back rounded vowel. The graphemes $\langle\mathrm{y}\rangle$ and $\langle\mathrm{w}\rangle$ represent glides that assimilate to epenthetic vowels (inserted to break up most CC sequences) usually yielding [i] and [u] respectively.

2. In Onggaya and Tomer, from the south of the language area, 'five' is nampao yswa, apparently ' 1 '-hand, and 'six' is nampao yswa naempr ' 1 '-hand +1. Nampao is, oddly, also found in these dialects in the form for 'four', nampao yempoka ' 1 ' -2 . 'One' and 'three' are identical to the Yanggandur forms. 
Table 3. Numerals in Kanum. Kanum numerals fall into three sets; the simple set ends at six, the moderate set reaches as far as 12, and the complex set is, in principle, infinite though no bases higher than $6^{5}$ have been recorded. With the complex set the range of possible additions and multiplications results in a completely productive numeral system; only some representative examples are given (and see the text for an example of the composition of a complex higher numeral).

\begin{tabular}{|c|c|c|c|c|}
\hline Simple & Moderate & & Complex & \\
\hline 1 naempr & aempy & & aempy & \\
\hline 2 yempoka & ynаоаетру & & упаоаетру & \\
\hline 3 ywaw & ylla & & ylla & \\
\hline 4 eser & eser & & eser & \\
\hline 5 swabra & tampwy & & $\operatorname{tamp}$ & \\
\hline 6 swy & traowao & & ptae & \\
\hline 7 & psymery aempy & ${ }^{\prime} 6{ }^{\prime}+1$ & aempy ptae & $1+6$ \\
\hline 8 & psymery ynaoaempy & $6{ }^{\prime}+2$ & ynaoaempy ptae & $2+6$ \\
\hline 9 & psymery ylla & ${ }^{\prime} 6{ }^{\prime}+3$ & ylla ptae & $3+6$ \\
\hline 10 & psymery eser & ${ }^{\prime} 6{ }^{\prime}+4$ & eser ptae & $4+6$ \\
\hline 11 & psymery tampwy & ${ }^{6} 6 \prime+5$ & tamp ptae & $5+6$ \\
\hline \multirow[t]{2}{*}{12} & $\begin{array}{l}\text { psymery traowao } \\
\text { or }\end{array}$ & ${ }^{\prime} 6+6$ & tarwmpao & 12 \\
\hline & yempoka traowao & $2 \times 6$ & & \\
\hline 13 & & & aempy tarwmpao & $1+12$ \\
\hline 14 & & & ynaoaempy tarwmpao & $2+12$ \\
\hline 15 & & & ylla tarwmpao & $3+12$ \\
\hline 16 & & & eser tarwmpao & $4+12$ \\
\hline 17 & & & tamp tarwmpao & $5+12$ \\
\hline 18 & & & ntamnao & 18 \\
\hline 19 & & & aempy ntamnao & $1+18$ \\
\hline 20 & & & ynaoaemy ntamnao & $2+18$ \\
\hline & & & $\cdots$ & \\
\hline 24 & 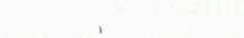 & & wramaekr & 24 \\
\hline 25 & & & $\begin{array}{l}\text { aempy wramaekr } \\
\ldots\end{array}$ & $1+24$ \\
\hline 30 & & & ptae wramaekr & $6+24$ \\
\hline 31 & & & aempy ptae wramaekr & $1+6+24$ \\
\hline $36\left(6^{2}\right)$ & & & (ntaop) ptae & (big) 6 \\
\hline 37 & & & aempy (ntaop) ptae & $1+$ (big) 6 \\
\hline 50 & & & ynaoaempy tarwmpao (ntaop) ptae & $2+12+36$ \\
\hline 100 & & & eser wramaekr ptae ynaoaempy & $4+24+(36 \times 2$ \\
\hline $216\left(6^{3}\right)$ & & & $\begin{array}{l}\cdots \\
\text { tarwmpao }\end{array}$ & \\
\hline $1296\left(6^{4}\right)$ & & & (ntaop) ntamnao & (big) 18 \\
\hline $7776\left(6^{5}\right)$ & & & (ntaop) wramaekr & (big) 24 \\
\hline
\end{tabular}

(the meaning of which is functionally similar to English -teen, but is used in a base- 6 system), is combined to produce the numbers ' 7 ' to ' 12 '. Notably, ' 12 ' is expressed either through pysymery traowao ' 6 ' +6 , or as yempoka pysymery $2 \times 6$, showing the optionality of a multiplication system in genesis. ${ }^{3}$

This second set cannot extend past ' 12 '; for that, a third set of numerals is employed. For this complex set the forms for 'one' through 'four' are identical to those of the moderate set (note that 'four' is consistently eser through all sets, the only form that is invariant). 'Five' in the complex set is not identical to the form in the moderate set, but is clearly reduced from tampwy. In the complex set addition now precedes, rather than follows, the radix, further distinguishing the different counting systems, so that while 'eight' is ' 6 ' +2 in the moderate set, it is $2+6$ in the complex set. For ' 12 ' we encounter a unique monomorphemic signifier, tarwmpao; similarly, '18' and ' 24 ', $3 \times 6$ and $4 \times 6$ respectively, have unique signifiers, ntamnao and wramaekr. ' 30 ' is expressed as $6+24$, and ' 36 ' is '(big) six', showing a clear use of exponentiation for $6 \times 6\left(6^{2}\right)$. The next exponent up, $6^{3}$, has a unique signifier, but the term used, tarwmpao, is identical to the word for ' 12 '. Optionally tarwmpay for ' 216 ' may be used, with the semi-regular nominalising suffix -ay (tarwmpay cannot be used to signify ' 12 '). Multiplicators follow the radix, thus ' 75 ' is expressed as ylla ptae ynoaaempy, $3+(36 \times 2)$. Large numbers, such as '500' or ' 1976 ', can easily be formed: ynaoaempy tarwmpay ynaoaempy ptae wramaekr ntaop ptae, ' $(2 \times 216)+(2+6+24+36)$ ', and ntamnao tarwmpay ylla ynaoaempy ptae wramaekr, ' $1296+(216 \times 3)+(2+(6+24))$ ', respectively, though it should be noted that some younger speakers are reinterpreting ntamnao '1296' as '1000' when counting, almost certainly under the influence of dealings with Indonesian currency (for which the 1000 is the lowest banknote of value, resulting in a system in which almost all products are priced in multiples of 1000). This means that ntamnao tamp is effectively ambiguous between ' 5000 ' ( $1000 \times 5$; new reading) or ' 6480 ' $(1296 \times 5$; old reading), although only the latter is prescriptively correct.

\section{Conclusions}

The fact that the three different systems are not independent of each other, sharing numerals to varying degrees and sharing the senary base, suggests that none of the systems has been imported from another culture. Marind, the dominant traditional culture of the area, had a restricted system analogous to that of One described above, and Indonesian, the modern lingua franca, has a regular

3. Notably, the multiplicative version yempoka pysymery $2 \times 6$ is more likely to be used as an approximation, while pysymery traowao $6+6$ is reserved for the exact count. Combinations with paoy 'approximately, roughly' are much more felicitous with yempoka pysymery than with pysymery traowao. 
decimal system that has not influenced the form, and has shown only slight inroads (as described in the preceding section) into influencing the function of Kanum numerals. In short, the Kanum numeral systems are all internal developments, and show the acquisition of a complex numeral system without the loss of first an earlier restricted system, and then a limited additive system. The moderate and complex systems were the linguistic response to a growing need for reckoning of larger and larger numbers; we can see that, although multiplicational concepts enter the moderate system, they are not fully developed, and in the complex system suppletion, rather than multiplication, characterises the multiples of six up to $6^{2}$. Only in the sequences beyond $6^{2}$ do we find multiplication as a regular feature, and even in this range the exponentials are not fully developed, with the terms for ' 12 ', ' 18 ', and ' 24 ' being "recycled" as higher powers.

While developing the more complex senary system the Kanum did not discard their earlier systems; these are still used when the objects counted will not exceed six, or twelve. The cognitive advantages are clear; with a system that extends only to six, or twelve, the finite set of numerals makes for more transparent processing. The use of the moderate, and particularly complex, numeral set acts as an instant and overt signal that a higher number is being expressed, communicating relevant information in a way that the first syllable of "one hundred thousand' does not. Conversely, the use of a numeral uniquely from the "simple" set, such as ywaw 'three', instantly cues the listeners that there will be no further multiplication or addition. Just because a restricted counting system is found in a language this does not imply the absence of a more complex one; conversely, the presence of a complex and regular system does not mean that restricted, or object-specific, sequences will not be found. Although numerals and numeral systems have been associated with "the progress of civilisation" (Crawfurd 1863), it is an oversimplification to expect that languages possess just one numeral system; rather, less productive systems with less use of exponentiation can be preserved for good cognitive reasons, even as more complex systems are developed.

Received: 26 April 2008

Revised: 27 July 2008

Australian National University

\section{References}

Beller, Sieghard \& Andrea Bender. 2008. The limits of counting: Numerical cognition between evolution and culture. Science 319. 213-215.

Comrie, Bernard. 2005. Numeral bases. In Martin Haspelmath, Matthew S. Dryer, David Gil \& Bernard Comrie (eds.), The world atlas of language structures, 530-533. Oxford: Oxfor University Press.

Crawfurd, John. 1863. On numerals as evidence of the progress of civilisation. Transactions of the Ethnological Society of London 2. 84-111.

Donohue, Mark. 2004. A grammar of the Skou language of New Guinea. Available online at http: //www.donohue.cc, following links to Academic, Languages, and Skou.

Gelman, Rochel \& C. R. Gallistel. 2004. Language and the origin of numerical concepts. Science 306. $441-443$

Laycock, D. C. 1975. Observations on number systems and semantics. In Stephen A. Wurm (ed.), Papuan languages and the New Guinea linguistics scene (Pacific Linguistics C-38), 219-233. Canberra: Australian National University.

Lean, Glendon Angove. 1992. Counting systems of Papua New Guinea and Oceania. Lae, Papua New Guinea: Papua New Guinea University of Technology doctoral dissertation. Available online at http://www.uog.ac.pg/glec/thesis/thesis.htm 


\section{Linguistic Typology}

Editor

Associate Editors
Editorial Assistant Editorial Address
Frans Plank

Universität Konstanz, Germany

Joan Bresnan Stanford University, Stanford, USA

Joan L. Bybee

University of New Mexico, Albuquerque, USA

Guglielmo Cinque

Università Ca'Foscari, Venezia, Italy

Alice C. Harris

State University of New York at Stony Brook, USA

Larry M. Hyman

University of California at Berkeley, USA

Maria Koptjevskaja-Tamm

Stockholms universitet, Sweden

Stephen C. Levinson

Max-Planck-Institute for Psycholinguistics,

Nijmegen, The Netherlands

Marianne Mithun

University of California at Santa Barbara, USA

Johanna Nichols

University of California at Berkeley, USA

Wolfgang Schellinger

Sprachwissenschaft Universität Konstanz 78457 Konstanz Germany

E-mail: frans.plank@uni-konstanz.de Fax: +49-7531-88 4190

MOUTON DE GRUYTER BERLIN - NEW YORK 


\section{Contents}

\section{Articles}

Mark Post

Adjectives in Thai: Implications for a functionalist typology of word classes 339 Gabriela Caballero, Michael J. Houser, Nicole Marcus, Teresa McFarland, Anne Pycha, Maziar Toosarvandani, and Johanna Nichols

Nonsyntactic ordering effects in noun incorporation

Mark Donohue

Complexities with restricted numeral systems

Language Profile

Françoise Rose

A typological overview of Emerillon, a Tupí-Guaraní language from French Guiana

\section{Book Reviews}

\section{John Hewson}

Aspect in Burmese, by Nicoletta Romeo

Gilbert Lazard

Alignment change in Iranian languages, by Geoffrey L. J. Haig

Mary Paster

Field linguistics, by Terry Crowley

Contents of Linguistic Typology, Volume 12 